\title{
„Nur ein Bruchteil der Gifte entsteht beim Lasern“
}

? Eine BfR-Untersuchung, an der Sie beteiligt waren, hat gezeigt, dass beim Lasern von farbigen Tätowierungen toxische Spaltprodukte gebildet werden: Aus Phthalocyanin-Blau wurden Substanzen wie Blausäure und Benzol freigesetzt. Hat Sie das Ergebnis überrascht? Berlien: Nein, überhaupt nicht. Diese Substanzen entstehen auch ohne Laserbehandlung, durch den natürlichen Zerfall des Farbstoffs. Wir wollten wissen, welche Substanzen in welchen Konzentrationen entstehen. Dazu haben wir unter kontrollierten Bedingungen reinen Farbstoff in einer Küvette mit dem Laser beschossen. So große Mengen an Tusche sind normalerweise gar nicht in der Haut. Folgeuntersuchungen an Schweinehautmodellen haben inzwischen gezeigt, dass dort bei einer Laserbehandlung erheblich geringere Konzentrationen freigesetzt werden.

Das Hauptproblem bei der Entfernung von Tätowierungen ist die Tätowierung an sich. $80 \%$ der eingebrachten Tusche sind nach zwei Monaten aus der oberflächlichen Schicht verschwunden und haben sich im Körper verteilt. Die Laserbehandlung trägt dann nur noch einen Bruchteil zur Entstehung von toxischen und allergenen Substanzen bei.

? Darf man großfächige blaue Tätowierungen also weiter mit dem Rubinlaser behandeln?

Berlien: Grundsätzlich ja. Entscheidend ist, wie bei jeder Lasertherapie, dass man nicht übertreibt und keine zu großen Flächen behandelt. Außerdem sollte man zwischen den Sitzungen mindestens 8 Wochen verstreichen lassen, damit das Lymphsystem sich wieder erholt und aufnahmefähig ist. Unter diesen Bedingungen ist die Belastung mit der Farbe oder auch mit Bruchstücken davon wie der Blausäure extrem gering. Gift ist eine Frage der Menge - Marzipan ohne Blausäure würde nicht schmecken. Nur bei sehr kleinen Tätowierungen empfehlen wir das Rausschneiden. Bei größeren Tätowierungen gibt es nichts Schonenderes als den Laser.

? Gilt das auch, wenn ein Patient auf eine Tätowierung allergisch reagiert hat?

Berlien: Nein. Allergische Reaktionen sind Ja-Nein-Reaktionen, hierfür genügt ein Molekül. Wenn ein Patient in der Tätowierung heftige Entzündungen hatte, verbietet sich eine Lasertherapie, bei der die Farbpartikel mobilisiert werden. Dann muss die Haut mit dem $\mathrm{CO}_{2}$-Laser abgetragen oder herausgeschnitten werden.

? Welche Voruntersuchungen sind nötig, bevor eine Tätowierung entfernt wird?

Berlien: Natürlich würde man gerne wissen, welche Substanzen eine Tätowierung enthält. Die meisten Tätowierungen kommen aus Urlaubsländern, sodass wir überhaupt nicht wissen, was drin ist. Zum Beispiel haben sogenannte Bio-Tattoos ein besonders großes Allergierisiko. Mit der Raman-Spektroskopie wäre es möglich, die Moleküle durch die Haut hindurch zu bestimmen; dieses Verfahren ist aber noch nicht im Einsatz. Routine-

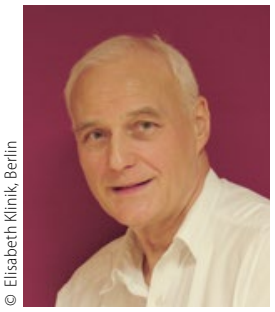

Prof. Dr. med. H.-Peter Berlien

Zentrum Lasermedizin

Elisabeth Klinik, Berlin

mäßig wird bei uns die optische Kohärenztomografie angewendet, um zu sehen, in welcher Schicht die Farbe liegt. Wenn es z. B. Farbseen gibt, dann ist das Versprengen per Laser keine Option, dann ist nur Abtragen möglich.

? Bieten neuere Verfahren wie der Picolaser im Hinblick auf toxische Effekte mehr Sicherheit?

Berlien: Ob Laserpulse von 900 Pikosekunden oder 10 Nanosekunden verwendet werden, macht keinen Unterschied. Ab Nanosekunden sind wir im nicht linearen Bereich, der den optischen Durchbruch und das Versprengen der Tuschepartikel bewirkt.

? Gibt es Fälle, in denen Sie Patienten von dem Entfernen einer Tätowierung abraten würden?

Berlien: Farbige Tätowierungen sind prinzipiell schwieriger zu entfernen. Wenn sie sich an einer Körperstelle befinden, wo die Abtragung bzw. die Operation mit einem unverhältnismäßig hohen Risiko belastet ist, und ich dazu weiß, dass das Motiv danach wie Mottenfraß aussieht, dann muss ich den Patienten darüber aufklären und ihm raten, dass er versucht, sich mit der Tätowierung zu arrangieren. Das gilt z. B. für großflächige Tätowierungen im Gesicht.

? Was müsste passieren, um Gesundheitsrisiken durch Tätowierungen zu reduzieren?

Berlien: Selbstbeschädigung ist in Deutschland nicht verboten. Aber wir müssen mehr Aufklärung betreiben. Eine Tätowierung ist eine Beschädigung des Körpers auf Lebenszeit, die nie zu $100 \%$ rückgängig zu machen ist. Eine der grauenvollsten Tätowierungen überhaupt ist das sogenannte Permanent-Make-up. Es befindet sich an sichtbaren Stellen, verursacht die meisten Nebenwirkungen und ist besonders schwierig zu entfernen, weil die Farbe dabei umschlagen kann. Wenn die Tätowierer nur halb so intensiv über die Nebenwirkungen ihrer Arbeit aufklären würden wie wir Ärzte über die Nebenwirkungen beim Entfernen von Tätowierungen, dann hätten wir nicht so viele Probleme damit.

Das Interview führte Dr. Beate Schumacher. 